\title{
The Design of Pension Pay Out Options WHEN THE HEALTH STATUS DURING RETIREMENT IS UNCERTAIN
}

\author{
MATHIAS KIFMANN
}

CESIFO WORKING PAPER NO. 2211

CATEGORY 3: SOCIAL PROTECTION

FEBRUARY 2008

\begin{abstract}
Presented AT CESIFo Venice SUMmer Institute, Workshop ON
'LONGEVITY AND ANNUITIZATION, JULY 2007
\end{abstract}
An electronic version of the paper may be downloaded
- from the SSRN website:
www.SSRN.com
- from the RePEc website:
www.RePEc.org
- from the CESifo website:
www.CESifo-group.org/wp 


\title{
The Design of Pension Pay Out Options WHEN THE HEALTH STATUS DURING RETIREMENT IS UNCERTAIN
}

\begin{abstract}
This paper examines the optimal design of pension plans when the health status during retirement is uncertain. Assuming that the health status affects both life expectancy and the marginal utility of consumption, choice between a lump-sum payment and an annuity can be welfare-enhancing if the health status is not observable by pension plans. This result holds if the marginal utility of consumption and life expectancy are negatively correlated. On equity grounds, a lump-sum option can be justified even if the marginal utility of consumption is independent of life expectancy.
\end{abstract}

JEL Code: G23, H55, D82.

Keywords: pensions, lump-sum withdrawal, annuities, longevity.

\author{
Mathias Kifmann \\ University of Augsburg \\ Universitätsstrasse 16 \\ 86159 Augsburg \\ Germany
}

Mathias.Kifmann@wiwi.uni-augsburg.de

January 2008

I thank Friedrich Breyer, Jean-Marie Lozachmeur, Wolfram Richter, Matthias Wrede and participants of the $8^{\text {th }}$ European Health Economics Workshop at the University of Magdeburg, the research seminar at the University of Dortmund and the CESifo Venice Summer Institute Workshop on "Longevity and Annuitization" for helpful comments and suggestions. This research is part of the project "Lebensarbeitszeit, Humankapitalbildung und Transfersystem" funded by the Deutsche Forschungsgemeinschaft under grant BR 740/15-1. 


\section{Introduction}

In a seminal paper, Yaari (1965) showed that individuals who maximize expected utility should annuitize all of their savings. Recently, Davidoff, Brown, and Diamond (2005) extended his analysis and showed that this result also holds under weaker conditions. Nevertheless, full annuitization remains the exception rather than the rule. The literature has therefore tried to explain why individuals only partially annuitize their wealth or choose not to annuitize at all. ${ }^{1}$

This paper deals with a particular deviation from Yaari's result. Frequently, individuals have a choice between a lump-sum payment and an annuity upon entering retirement. For example, this is the case in many private pension plans. Also publicly regulated programmes such as Chile's funded pension system, the Swiss occupational pension scheme or state-subsidized supplementary private pensions in Germany ('Riester pensions') allow such a choice.

An important question is whether the possibility to select a lump sum can be desirable. In a standard model, this option can only reduce welfare since individuals with a low life expectancy will opt for the lump sum. This reduces the redistribution from short-living to long-living individuals which is optimal ex ante when life expectancy is still uniform (Brugiavini, 1993, and Sheshinski, 2004).

The standard model, however, assumes that the utility function is independent of life expectancy. This is questionable as life expectancy is closely related to the health status which is likely to have an impact on the utility function. In this paper, we show that considering the links between life expectancy, health and utility can make a lump-sum option valuable. Specifically, we find that rational individuals might prefer a choice between a lump-sum payment and an annuity if the health status during retirement is uncertain and unobservable. This is the case if the marginal utility of consumption and life expectancy are negatively correlated. ${ }^{2}$

\footnotetext{
${ }^{1}$ Possible explanations include inferior returns to annuities due to administrative costs and selection effects (Friedman and Warshawsky, 1988, 1990, Mitchell, Poterba, Warshawsky, and Brown, 1999), bequest motives (Kotlikoff and Summers, 1981, Hurd, 1989, Bernheim, 1991), incomplete markets (Yagi and Nishigaki, 1993, Davidoff, Brown, and Diamond, 2005), within family-risk sharing (Kotlikoff and Spivak, 1981, Brown and Poterba, 2000), and pre-existing annuities from public pensions (Bernheim, 1991).

${ }^{2}$ A similar result has been obtained by Diamond (2003) in an optimal income tax framework. He finds a lump-sum option to be optimal if life expectancy and productivity are positively correlated.
} 
A related result is obtained by Direr (2007) who extends the standard model by considering uninsurable expenses during old age. As in the present paper, individuals discover their survival probabilities after buying an annuity contract. Individuals with high life expectancy face an uninsurable expenditure risk early in old age. Direr shows that a flexible annuity plan is optimal which allows a withdrawal. It smoothes consumption for individuals who experience the expenditure shock. The existence of short-lived individuals, however, puts a limit on the withdrawal. ${ }^{3}$ The paper is structured as follows. In Section 2, we present the basic model and derive conditions under which choice in a pension plan is optimal. Section 3 extends the basic model in various directions. In Section 4, we discuss the implications for public pensions. Here we show that a lump-sum option can also be justified on equity grounds. For a strictly concave social welfare function, this is the case even if the marginal utility of consumption is independent of life expectancy. Section 5 concludes and points out directions for further research.

\section{The basic model}

\subsection{Health status, marginal utility and life expectancy}

Individuals are initially identical. They invest wealth $\Omega$ in a pension plan before entering retirement. Retirement is reached with probability $\delta<1$. Upon retirement, the health status $h=g, b$ of individuals is revealed. With probability $\pi$ the 'good' state $g$ arises, with probability $1-\pi$ the health status is 'bad'. The health status has implications both for life expectancy and the marginal utility of consumption:

\footnotetext{
${ }^{3}$ Zhang and Tang (2007) examine the optimal choice with an uninsurable expenditure risk in absence of a withdrawal option. They find that individuals may then prefer not to fully annuitize their wealth.
} 


\section{- Health status and life expectancy}

Individuals with health status $b$ will only live one period after retirement (period 1). With status $g$, one can live up to two periods. The survival probability for period 2 is $0<\rho<1$. Individuals possess information on their life expectancy. ${ }^{4}$

\section{- Health status and utility}

Utility is state-dependent. In state $g$, utility in each period is $u\left(c_{t}\right)$ where $c_{t}$ is consumption in period $t=1,2$. In stage $b$, utility is $\alpha u\left(c_{t}\right)$, with $u^{\prime}\left(c_{t}\right)>0, u^{\prime \prime}\left(c_{t}\right)<0, \lim _{c_{t} \rightarrow 0} u^{\prime}\left(c_{t}\right)=\infty$ and $\alpha>0$. We leave open whether $\alpha \gtrless 1$, i.e. whether marginal utility of consumption is higher in state $b$ or $g$ for a given level of consumption. ${ }^{5}$ In particular, we do not find $\alpha>1$ implausible. ${ }^{6}$ Knowledge of nearby early death may make consumption more valuable. For example, individuals may want to spend money on an expensive trip they always dreamed of. ${ }^{7}$

For simplicity, consumption before period 1 is not modeled since it does not affect the structure of the optimal pension plan. Only the amount invested in the annuity may vary. Furthermore, we assume that the interest rate is zero. Individuals do not discount the future and have no bequest motive. Finally, we abstract from further financial risks, e.g. medical expenditure, by implicitly assuming that these are fully insured. Expected utility is thus given by

$$
E U=\delta\left(\pi\left(u\left(c_{1}^{g}\right)+\rho u\left(c_{2}^{g}\right)\right)+(1-\pi) \alpha u\left(c_{1}^{b}\right)\right) .
$$

\footnotetext{
${ }^{4}$ For evidence on this hypothesis, see Hurd and McGarry (1995).

${ }^{5}$ In the following, we frequently drop the qualification "for a given level of consumption" and simply speak of "marginal utility of consumption being higher in state $b(g)$ " when it is clear that we refer to $\alpha>1(<1)$.

${ }^{6}$ Viscusi and Evans (1990) find evidence for a lower marginal utility when the health status declines. However, this study is based on chemical workers and not on elderly. In a further study using survey data on adults approaching middle age, Evans and Viscusi (1991) could not identify an effect of health on the marginal utility of consumption.

${ }^{7}$ In our set-up, $\alpha>1$ implies that individuals are actually better off in state $b$. However, we can also write utility in the bad state as $\alpha u(c)-\kappa$ which is compatible with higher marginal utility of consumption but lower total utility. Since only marginal utility of consumption is important in the following, we stick to our simpler version.
} 


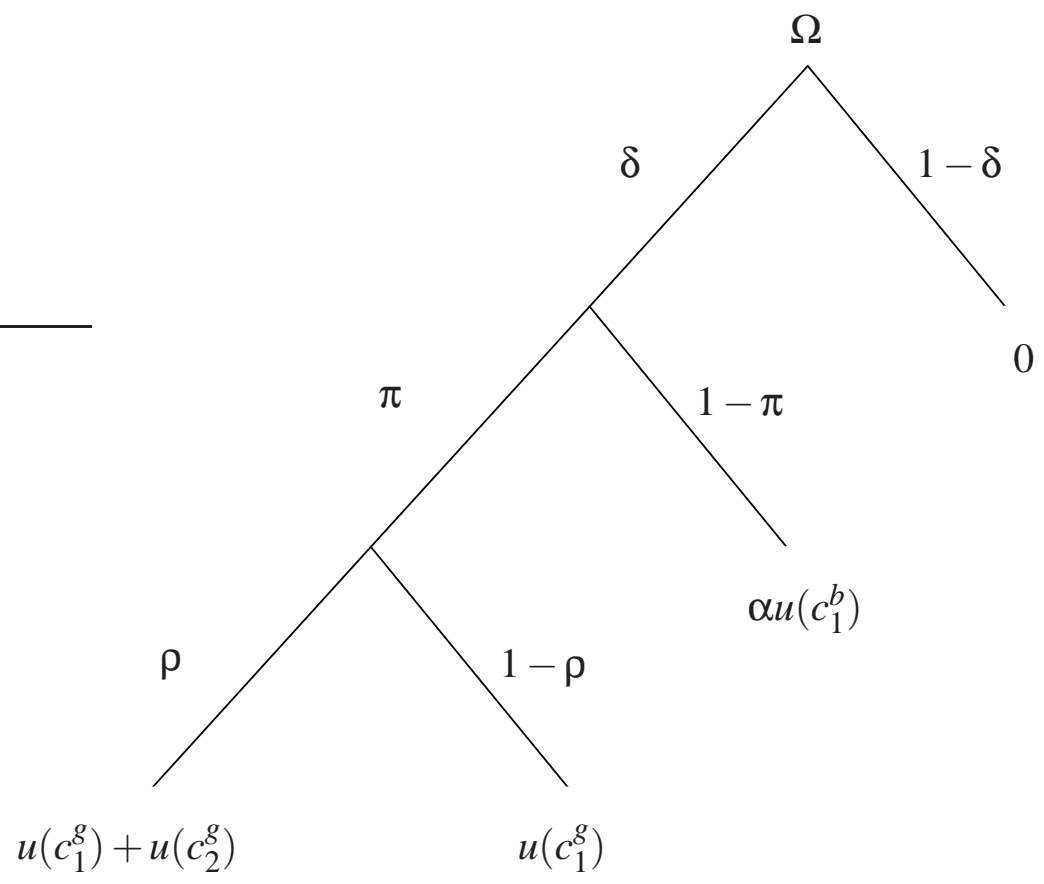

Figure 1: States of nature and utilities

Figure 1 shows the different states of nature and the corresponding utilities. Three risks which individuals would like to insure against through a pension plan can be identified:

(i) the risk to reach retirement,

(ii) the risk that marginal utility differs between the health states,

(iii) the longevity risk in state $g$.

We assume that pension plans are actuarially fair and maximize expected utility of individuals. This can be interpreted as the outcome of competition on the market for pension plans. Alternatively, this assumption can be justified by a public pension scheme set up to meet this objective (see Section 4). Furthermore, we rule out that individuals can draw loans on future pension payments and guarantee repayments through life insurance. Therefore, it is not possible to borrow against future income. 


\subsection{Observable health status}

If health status is observable, pension plans can make their payments dependent on the health status and the age of the individual. We therefore solve the following problem

$$
\begin{aligned}
\max _{\substack{g \\
c_{1}^{g}, c_{2}^{g}, c_{1}^{b}}} E U & =\delta\left(\pi\left(u\left(c_{1}^{g}\right)+\rho u\left(c_{2}^{g}\right)\right)+(1-\pi) \alpha u\left(c_{1}^{b}\right)\right) \\
\text { s.t. } \quad \Omega & =\delta\left(\pi c_{1}^{g}+\pi \rho c_{2}^{g}+(1-\pi) c_{1}^{b}\right) .
\end{aligned}
$$

From the first-order conditions, we obtain that marginal utility of consumption must be the same in all states and periods, i.e.

$$
u^{\prime}\left(c_{1}^{g *}\right)=u^{\prime}\left(c_{2}^{g *}\right)=\alpha u^{\prime}\left(c_{1}^{b *}\right)
$$

This implies

$$
c_{1}^{g *}=c_{2}^{g *}=c^{g *}, \quad c_{1}^{b *} \gtrless c^{g *} \Leftrightarrow \alpha \gtrless 1 .
$$

Thus, a constant annuity is optimal in the good health state. The payment in the bad health state is larger if marginal utility of consumption is higher for a given level of consumption.

Proposition 2.1. If the health status is observable, then it is optimal to pay out $c_{1}^{b *}$ in the bad health state and to provide an annuity $c^{g *}$ in the good health state. The payment in the bad health state is larger than the annuity if and only if marginal utility of consumption is higher in that state.

\subsection{Unobservable health status}

In the following, we assume that the health status is not observable. Furthermore, pension plans do not possess any information on the consumption of individuals which would allow them to identify the type. Then the optimal pension plan must be incentive-compatible, i.e. no type should have an advantage by claiming to be the other type. For $b$-types, the incentive constraint is

$$
\alpha u\left(c_{1}^{b}\right) \geq \alpha u\left(c_{1}^{g}\right) \quad \Leftrightarrow \quad c_{1}^{b} \geq c_{1}^{g} .
$$


Clearly, the one-period payments for $b$-types cannot be smaller than the firstperiod payments for $g$-types. Note that the first best violates (ICB) if $c_{1}^{g}>c_{1}^{b}$ which corresponds to $\alpha<1$, i.e. lower marginal utility of consumption in the bad state of health.

Incentive compatibility for $g$-types could be ensured if pension plans were able to punish $g$-types in period 2 if they claimed a one-period payment since only $g$-types can be alive in this period. However, it is doubtful whether courts would enforce it. We therefore do not consider this possibility. ${ }^{8}$

??Except for Section 3.5, we also rule out that pension plans can observe the levels of consumption. Types can therefore not be identified by their first-period consumption.

If $g$-types pretend to be $b$-types, they exchange a one-period payment for a payment stream over two periods. This raises the question how they finance their consumption in period 2. Their preferred method is to annuitize the one-period payment. In this section, we assume that they are able to do so, e.g. because pensions plan are not able to monitor further annuity purchases. ${ }^{9}$ The price $g$-types must pay for an annuity will be $\rho$ per unit consumption in period 2 since only $g$ types will demand annuities. $g$-types will therefore buy annuities up to the point where $u^{\prime}\left(\hat{c}_{1}^{g}\right)=u^{\prime}\left(\hat{c}_{2}^{g}\right)$. If $g$-types claim to be $b$-types and receive $c_{1}^{b}$ in period 1 , their consumption is therefore given by $\hat{c}_{1}^{g}=\hat{c}_{2}^{g}=c_{1}^{b} /(1+\rho)$ yielding expected utility in period 1

$$
E U^{g}(t=1)=u\left(\hat{c}_{1}^{g}\right)+\rho u\left(\hat{c}_{2}^{g}\right)=(1+\rho) u\left(c_{1}^{b} /(1+\rho)\right) .
$$

Therefore the incentive constraint for $g$-types is

$$
u\left(c_{1}^{g}\right)+\rho u\left(c_{2}^{g}\right) \geq(1+\rho) u\left(c_{1}^{b} /(1+\rho)\right) .
$$

The first-best solution violates (ICG) if $c_{1}^{b *}>(1+\rho) c^{g *}$, i.e. if the payment for $b$ types is larger than the present value of the annuity for $g$-types. This is the case if $\alpha$ exceeds a critical value $\tilde{\alpha}>1$. For example, if $u(c)=\ln (c)$, we have $c_{1}^{b *}=\alpha c^{g *}$ in the first best which yields a critical value $\tilde{\alpha}=1+\rho$.

\footnotetext{
${ }^{8}$ See also Section 3.5 where we consider that $b$-types may live up to period 2.

${ }^{9}$ In Section 3.1, we allow pensions plans to prohibit the purchase of further annuities.
} 


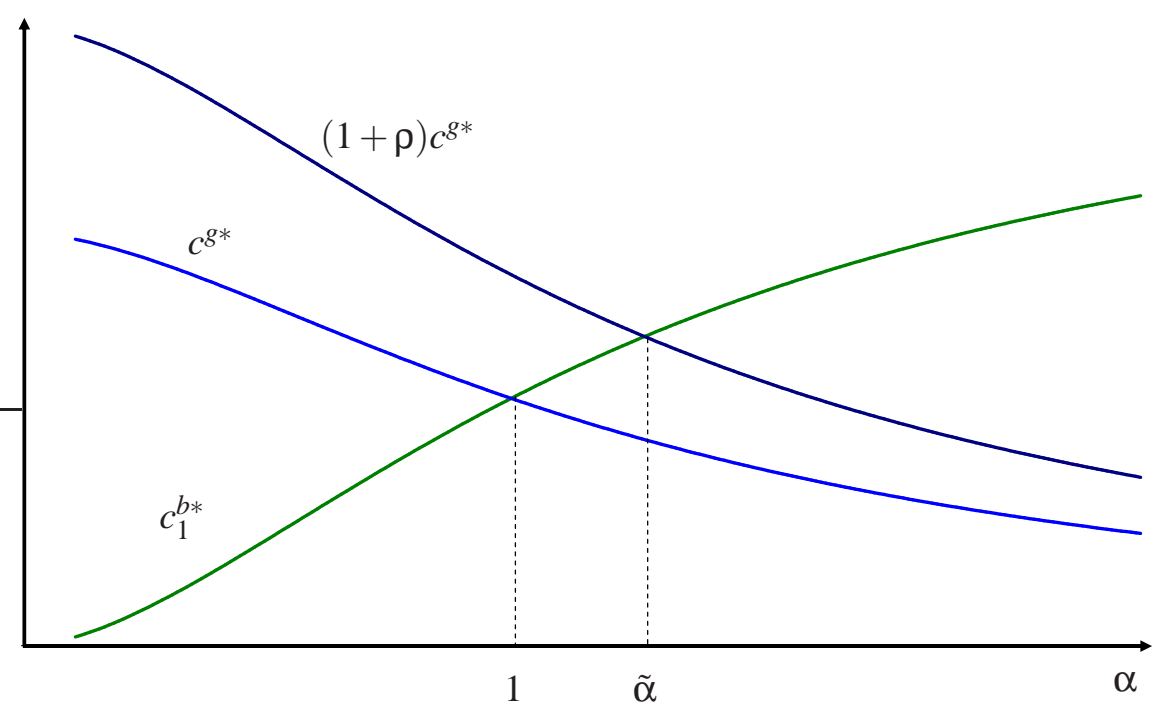

Figure 2: First-best consumption and incentive compatiblity

Figure 2 illustrates the conflict between the first best and incentive compatibility. It shows first-best consumption $c^{g *}$ and $c_{1}^{b *}$ and the present value $(1+\rho) c^{g *}$ as functions of $\alpha$. If $\alpha<1$, then $c_{1}^{b *}<c^{g *}$ and the incentive-constraint for $b$-types is violated. $\alpha>\tilde{\alpha}$ implies $c_{1}^{b *}>(1+\rho) c^{g *}$ and $g$-types have the incentive to claim $c_{1}^{b *}$ and convert this into an annuity. We therefore find that the first best is incentive-compatible only if $\alpha \in[1 ; \tilde{\alpha}]$. In this case, the first best can be implemented by giving individuals a choice between a lump-sum payment $c_{1}^{b *}$ and an annuity $c_{t}^{g *}$. Individuals will self-select since $c_{1}^{b *} \geq c^{g *}$ and $(1+\rho) c^{g *} \geq c_{1}^{b *}$. However, if $\alpha<1$ or $\alpha>\tilde{\alpha}$, only a second-best solution is possible. We consider both cases in the following.

\section{Second-best solution for $\alpha<1$}

If $\alpha<1$, then marginal utility of consumption and life expectancy are positively correlated. The first best is not compatible with the incentive constraint for $b$ types (ICB). In the second-best solution, this constraint will therefore be binding. To determine the second best, we solve the problem

$$
\max _{\substack{b \\ c_{1}^{b}, c_{1}^{g}, c_{2}^{g}}} E U=\delta\left(\pi\left(u\left(c_{1}^{g}\right)+\rho u\left(c_{2}^{g}\right)\right)+(1-\pi) \alpha u\left(c_{1}^{b}\right)\right)
$$


s.t.

$$
\begin{aligned}
& \Omega=\delta\left(\pi c_{1}^{g}+\pi \rho c_{2}^{g}+(1-\pi) c_{1}^{b}\right) \\
& \hat{c}_{1}^{b}=\hat{c}_{1}^{g}=c_{1}
\end{aligned}
$$

where (4) is the incentive constraint (ICB) with equality sign. Substituting (4) yields the Lagrangian

$$
\mathcal{L}=\delta\left(\pi\left(u\left(c_{1}\right)+\rho u\left(c_{2}^{g}\right)\right)+(1-\pi) \alpha u\left(c_{1}\right)\right)+\lambda\left\{\Omega-\delta\left(c_{1}+\pi \rho c_{2}^{g}\right)\right\}
$$

with the first-order conditions

$$
\begin{aligned}
& \frac{\partial \mathcal{L}}{\partial c_{1}}=\delta(\pi+(1-\pi) \alpha) u^{\prime}\left(c_{1}\right)-\lambda \delta=0 \\
& \frac{\partial \mathcal{L}}{\partial c_{2}^{g}}=\delta \pi \rho u^{\prime}\left(c_{2}^{g}\right)-\lambda \delta \pi \rho=0 \\
& \frac{\partial \mathcal{L}}{\partial \lambda}=\Omega-\delta\left(c_{1}+\pi \rho c_{2}^{g}\right)=0 .
\end{aligned}
$$

We obtain

$$
(\pi+(1-\pi) \alpha) u^{\prime}\left(c_{1}\right)=u^{\prime}\left(c_{2}^{g}\right) .
$$

Since $(\pi+(1-\pi) \alpha)<1$, this implies $c_{1}<c_{2}^{g}$, i.e. the annuity rises over time. ${ }^{10}$ Thus, the incentive for $b$-types to claim to be $g$-types leads to a distorted annuity for $g$-types. Ex ante, of course, all individuals are worse off. Compared to first best, it can be shown that $c_{1}^{b *}<c_{1}<c^{g *} .{ }^{11}$ A priori, it is not clear whether $c_{2}^{g} \gtrless$ $c^{g *} \cdot 12$

Second-best solution for $\alpha>\tilde{\alpha}$

In this case, marginal utility of consumption and life expectancy are strongly negatively correlated. The first best violates the incentive constraint for $g$-types (ICG). The second best can be found by solving the problem

$$
\max _{\substack{b \\ c_{1}^{b}, c_{1}^{g}, c_{2}^{g}}} E U=\delta\left(\pi\left(u\left(c_{1}^{g}\right)+\rho u\left(c_{2}^{g}\right)\right)+(1-\pi) \alpha u\left(c_{1}^{b}\right)\right)
$$

\footnotetext{
${ }^{10}$ Note that we ruled out borrowing against future payments.

${ }^{11}$ Equation (8) implies $\alpha u^{\prime}\left(c_{1}\right)<u^{\prime}\left(c_{2}^{g}\right)$. Taking into account the budget constraint, the firstbest condition (3) and the incentive constraint (4), this is only possible if $c_{1}>c_{1}^{b *}$. Furthermore, $c_{1} \geq c^{g *}$ is not compatible with the budget constraint since $c_{2}^{g}>c_{1}$.

${ }^{12}$ For constant relative risk aversion $\psi$, it can be shown that $c_{2}^{g}>c^{g *}$ if and only if $\psi<1$.
} 
s.t.

$$
\begin{gathered}
\Omega=\delta\left(\pi c_{1}^{g}+\pi \rho c_{2}^{g}+(1-\pi) c_{1}^{b}\right) \\
u\left(c_{1}^{g}\right)+\rho u\left(c_{2}^{g}\right)=(1+\rho) u\left(c_{1}^{b} /(1+\rho)\right)
\end{gathered}
$$

where (10) is the incentive constraint (ICG) with equality sign. The Lagrangian is

$$
\begin{aligned}
\mathcal{L}= & \delta\left(\pi\left(u\left(c_{1}^{g}\right)+\rho u\left(c_{2}^{g}\right)\right)+(1-\pi) \alpha u\left(c_{1}^{b}\right)\right) \\
& +\lambda\left\{\Omega-\delta\left(\pi c_{1}^{g}+\pi \rho c_{2}^{g}+(1-\pi) c_{1}^{b}\right)\right\} \\
& +\mu\left\{u\left(c_{1}^{g}\right)+\rho u\left(c_{2}^{g}\right)-(1+\rho) u\left(c_{1}^{b} /(1+\rho)\right)\right\}
\end{aligned}
$$

with the first-order conditions

$$
\begin{aligned}
& \frac{\partial \mathcal{L}}{\partial c_{1}^{g}}=\delta \pi u^{\prime}\left(c_{1}^{g}\right)-\lambda \delta \pi+\mu u^{\prime}\left(c_{1}^{g}\right)=0 \\
& \frac{\partial \mathcal{L}}{\partial c_{2}^{g}}=\delta \pi \rho u^{\prime}\left(c_{2}^{g}\right)-\lambda \delta \pi \rho+\mu \rho u^{\prime}\left(c_{2}^{g}\right)=0 \\
& \frac{\partial \mathcal{L}}{\partial c_{1}^{b}}=\delta(1-\pi) \alpha u^{\prime}\left(c_{1}^{b}\right)-\lambda \delta(1-\pi)-\mu u^{\prime}\left(c_{1}^{b} /(1+\rho)\right)=0 \\
& \frac{\partial \mathcal{L}}{\partial \lambda}=\Omega-\delta\left(\pi c_{1}^{g}+\pi \rho c_{2}^{g}+(1-\pi) c_{1}^{b}\right)=0 \\
& \frac{\partial \mathcal{L}}{\partial \mu}=u\left(c_{1}^{g}\right)+\rho u\left(c_{2}^{g}\right)-(1+\rho) u\left(c_{1}^{b} /(1+\rho)\right)=0 .
\end{aligned}
$$

From (11) und (12) we obtain

$$
u^{\prime}\left(c_{1}^{g}\right)=u^{\prime}\left(c_{2}^{g}\right) \quad \Rightarrow \quad c_{1}^{g}=c_{2}^{g}=c^{g}
$$

and a standard annuity is optimal for $g$-types. Substituting into (10) yields

$$
(1+\rho) u\left(c^{g}\right)=(1+\rho) u\left(c_{1}^{b} /(1+\rho)\right) \quad \Rightarrow \quad c_{1}^{b}=(1+\rho) c^{g}>c^{g},
$$

i.e. the lump-sum payment for $b$-types and the present value of the annuity for $g$-types are the same. In the first best, in contrast, $\alpha>\tilde{\alpha}$ implies that the present value of the annuity is smaller than the payment for $b$-types (see Figure 2). Thus, the annuity level for people in good health must be larger in the second best and the payment for $b$-types must be smaller. Substituting (16) and (17) into the budget constraint (9), we obtain

$$
c_{1}^{b}=\frac{\Omega}{\delta} \quad \text { and } \quad c_{1}^{g}=c_{2}^{g}=\frac{\Omega}{\delta(1+\rho)}
$$




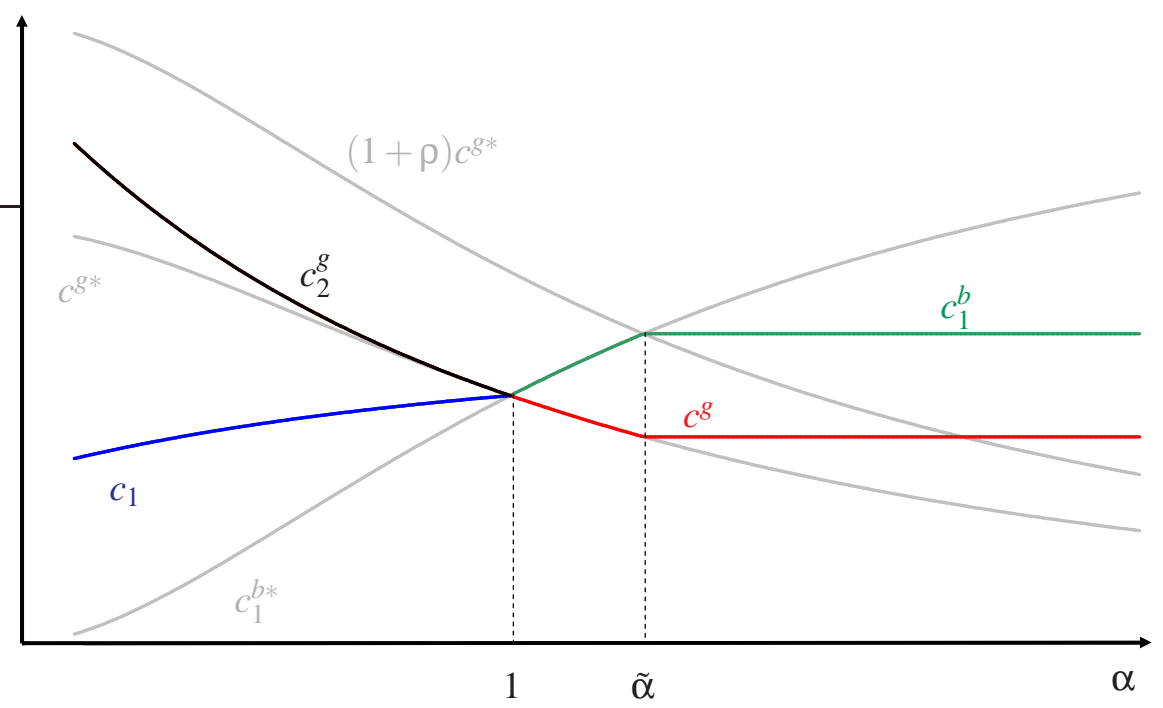

Figure 3: Second-best consumption

as the optimal solution. It can be implemented by giving individuals a choice between a lump-sum payment and an annuity. ${ }^{13}$

Proposition 2.2. If the health status is unobservable, then the first best can only be implemented if life expectancy and marginal utility of consumption are weakly negatively correlated $(1 \leq \alpha \leq \tilde{\alpha})$. Otherwise, a second-best solution prevails. It is optimal to give individuals a choice between a lump-sum payment and an annuity if life expectancy and marginal utility of consumption are negatively correlated $(\alpha \geq 1)$. Otherwise, an annuity which increases over time is preferable.

Figure 3 illustrates the second-best solution. For $\alpha<1$, we have $c_{1}^{b *}<c_{1}<c^{g *}$ and $c_{2}^{g}>c^{g *}$, the latter being due to a utility function with constant relative risk aversion less than one. For $\alpha>\tilde{\alpha}, c_{1}^{b}$ and $c^{g}$ are given by (18).

\footnotetext{
${ }^{13}$ It is also possible to implement the second best by paying out a lump sum $c_{1}^{b}$ which is then annuitized by $g$-types. In Section 3.1 where we allow pension plans to prohibit the purchase of further annuities, however, this solution is inferior to a choice between a lump-sum payment and an annuity (see footnote 14).
} 


\section{Extensions}

In this section, we extend the basic model in various directions to check whether choice between a lump-sum payment and an annuity at retirement can still remain optimal. We consider the following extensions:

1. In Subsection 3.1, we allow pension plans to monitor the purchase of further annuities.

2. Imperfect correlation between marginal utility of consumption and life expectancy is considered in Subsection 3.2.

3. Subsection 3.3 assumes that both types have the same identical close-todeath utility $\alpha u\left(c_{t}\right)$.

4. The possibility of moral hazard due to a state-guaranteed minimum income is examined in Subsection 3.4

5. Subsection 3.5 allows for a positive survival probability to period 2 for individuals in bad health.

\subsection{Monitoring of annuity purchases possible}

If annuity purchases can be monitored, pension plans can make it more difficult for $g$-types to pretend to be $b$-types by prohibiting annuitization of the lump-sum payment. Then the only way for $g$-types to transfer income to period 2 is to save. If they chose the lump-sum payment, they will therefore solve the problem

$$
\max E U^{g}=u\left(c_{1}^{g}\right)+\rho u\left(c_{2}^{g}\right) \quad \text { s.t. } \quad c_{1}^{g}+c_{2}^{g}=c_{1}^{b} .
$$

At the optimum

$$
u^{\prime}\left(\hat{c}_{1}^{g}\left(c_{1}^{b}\right)\right)=\rho u^{\prime}\left(\hat{c}_{2}^{g}\left(c_{1}^{b}\right)\right)
$$

and therefore $\hat{c}_{1}^{g}\left(c_{1}^{b}\right)>\hat{c}_{2}^{g}\left(c_{1}^{b}\right)$ as $\rho<1$. With probability $1-\rho$, individuals will leave unintended bequests $c_{2}^{g}\left(c_{1}^{b}\right)$.

The new incentive constraint for $g$-types is

$$
u\left(c_{1}^{g}\right)+\rho u\left(c_{2}^{g}\right) \geq u\left(\hat{c}_{1}^{g}\left(c_{1}^{b}\right)\right)+\rho u\left(\hat{c}_{2}^{g}\left(c_{1}^{b}\right)\right) .
$$


Clearly, the RHS of (21) will be smaller than the RHS of (ICG) for a given value of $c_{1}^{b}$. Thus, the corresponding critical value of $\tilde{\alpha}_{\text {mon }}$ will be higher than the critical value $\tilde{\alpha}$ without monitoring and the first best can be implemented for a larger range of $\alpha$. For example, if $u(c)=\ln (c)$, we obtain

$$
(1+\rho) \ln \left(c^{g}\right) \geq \ln \left(\frac{c_{1}^{b}}{1+\rho}\right)+\rho \ln \left(\frac{\rho c_{1}^{b}}{1+\rho}\right) .
$$

With the first-best condition $c^{b}=\alpha c^{g}$, this yields a critical value

$$
\tilde{\alpha}_{\text {mon }}=(1+\rho) \rho^{-\frac{\rho}{1+\rho}}>1+\rho=\tilde{\alpha} \text {. }
$$

If $\alpha>\tilde{\alpha}_{\text {mon }}$, then we obtain a similar result as in section 2.3. The second best can be implemented by choice between a lump-sum payment and a constant annuity. ${ }^{14}$ However, the present value of the annuity for $g$-types is lower than lump-sum payment for $b$-types.

Proposition 3.1. If pensions plans can monitor further annuity purchases, then the first best can be implemented for higher levels of the marginal utility of consumption in the bad health state.

\subsection{Heterogenous marginal utility}

Now we relax the assumption that marginal utility is unique given life expectancy. In each health state, marginal utility can take different values. In state $b$, utility is $\alpha u\left(c_{1}^{b}\right)$ with $\alpha \in\left[\alpha_{1}, \alpha_{2}\right]$. In state $g$, utility is $\beta u\left(c_{1}^{g}\right)+\rho \beta u\left(c_{2}^{g}\right)$ with $\beta \in\left[\beta_{1}, \beta_{2}\right]$. Expected utility is given by

$$
E U=\delta\left(\pi \bar{\beta}\left(u\left(c_{1}^{g}\right)+\rho u\left(c_{2}^{g}\right)\right)+(1-\pi) \bar{\alpha} u\left(c_{1}^{b}\right)\right)
$$

where $\bar{\alpha}$ and $\bar{\beta}$ are the average values of $\alpha$ and $\beta$.

In the first best, we obtain that the marginal utility of consumption should be equalized across all states, i.e.

$$
\forall \alpha, \beta \quad \alpha u^{\prime}\left(c_{1}^{b}(\alpha)\right)=\beta u^{\prime}\left(c_{t}^{g}(\beta)\right), \quad t=1,2 .
$$

\footnotetext{
${ }^{14}$ As opposed to the basic model, only paying out a lump-sum payment $c_{1}^{b}$ cannot implement the second best since $g$-types are not allowed to annuitize.
} 
The optimal pay outs are therefore increasing in $\alpha$ and $\beta$. This implies that the first best requires knowledge of these parameters which is highly unlikely. Thus, even if the health status is observable, only a second-best solution can be implemented. Normalizing $\bar{\beta}=1$, we obtain the following condition

$$
u^{\prime}\left(c_{1}^{g}\right)=u^{\prime}\left(c_{2}^{g}\right)=\bar{\alpha} u^{\prime}\left(c_{1}^{b}\right)
$$

which states that marginal utility of consumption should be equalized on average across health states.

When the health status is not observable, the incentive constraints are

$$
\forall \alpha \quad \alpha u\left(c_{1}^{b}\right) \geq \alpha u\left(c_{1}^{g}\right)
$$

and

$$
\forall \beta \quad \beta u\left(c_{1}^{g}\right)+\rho \beta u\left(c_{2}^{g}\right) \geq(1+\rho) \beta u\left(c_{1}^{b} /(1+\rho)\right) .
$$

Note that $\alpha$ and $\beta$ have no impact on the incentive constraints. Thus, they are identical to (ICB) and (ICG) and we can use the results from above by interpreting $\alpha$ as the average $\bar{\alpha}$. Thus, although the first best cannot be implemented, giving individuals a choice between a lump-sum payment and an annuity is still optimal if $\bar{\alpha} \geq 1$. For $1 \leq \bar{\alpha} \leq \tilde{\alpha}$, we obtain a second-best solution, otherwise a third best arises.

Proposition 3.2. If marginal utility of consumption and life expectancy are only imperfectly correlated and neither marginal utility of consumption nor the health status are observable, then it is optimal to give individuals a choice between a lump-sum payment and an annuity if life expectancy and marginal utility are negatively correlated. Otherwise, an annuity which increases over time is preferable.

\subsection{Identical close-to-death utility}

One argument for state-dependent utility is closeness to certain death. If this reasoning applies, we must also assume that the utility function is $\alpha u(c)$ for $g$-types in period 2. Expected utility is then given by

$$
E U=\delta\left(\pi\left(u\left(c_{1}^{g}\right)+\rho \alpha u\left(c_{2}^{g}\right)\right)+(1-\pi) \alpha u\left(c_{1}^{b}\right)\right) .
$$


Maximizing expected utility subject to the wealth constraint (2) leads to

$$
u^{\prime}\left(c_{1}^{g *}\right)=\alpha u^{\prime}\left(c_{2}^{g *}\right)=\alpha u^{\prime}\left(c_{1}^{b *}\right)
$$

which implies for the first best

$$
c_{1}^{b *}=c_{2}^{g *} \gtrless c_{1}^{g *} \Leftrightarrow \alpha \gtrless 1 .
$$

Thus, consumption in the last period of life is identical for both types. Secondperiod consumption in good health is higher if marginal utility is larger.

If the health status cannot be observed, the incentive constraint (ICB) for $b$-types remains unaffected and the first best cannot be implemented for $\alpha<1$. In this case, consumption must be the same for both types in period 1. The Lagrangian is

$$
\mathcal{L}=\delta\left(\pi\left(u\left(c_{1}\right)+\rho \alpha u\left(c_{2}^{g}\right)\right)+(1-\pi) \alpha u\left(c_{1}\right)\right)+\lambda\left\{\Omega-\delta\left(c_{1}+\pi \rho c_{2}^{g}\right)\right\} .
$$

with the first-order conditions

$$
\begin{aligned}
& \frac{\partial \mathcal{L}}{\partial c_{1}}=\delta(\pi+(1-\pi) \alpha) u^{\prime}\left(c_{1}\right)-\lambda \delta=0 \\
& \frac{\partial \mathcal{L}}{\partial c_{2}^{g}}=\delta \pi \rho \alpha u^{\prime}\left(c_{2}^{g}\right)-\lambda \delta \pi \rho=0 \\
& \frac{\partial \mathcal{L}}{\partial \lambda}=\Omega-\delta\left(c_{1}+\pi \rho c_{2}^{g}\right)=0 .
\end{aligned}
$$

We obtain

$$
(\pi+(1-\pi) \alpha) u^{\prime}\left(c_{1}\right)=\alpha u^{\prime}\left(c_{2}^{g}\right) .
$$

Since $\pi+(1-\pi) \alpha>\alpha$, we have $c_{1}>c_{2}^{g}$, i.e. the annuity falls over time. This result also holds in the first best. However, $g$-types' intertemporal consumption is distorted since $\pi+(1-\pi) \alpha<1$ which implies $u^{\prime}\left(c_{1}\right)>\alpha u^{\prime}\left(c_{2}^{g}\right)$. As in the basic model, $g$-types consume too much in the second period.

Turning to the case $\alpha>1$, we need to consider the incentive constraint for $g$-types if the health status is not observable. It is different from the basic model since $g$-types will not buy a constant annuity if they select the payment for $b$-types. Taking into account their optimal choice of consumption $\hat{c}_{t}^{g}\left(c_{1}^{b}\right)$ in period $t$ if $g$ types choose the lump-sum payment, the incentive constraint is

$$
u\left(c_{1}^{g}\right)+\rho \alpha u\left(c_{2}^{g}\right) \geq u\left(\hat{c}_{1}^{g}\left(c_{1}^{b}\right)\right)+\rho \alpha u\left(\hat{c}_{2}^{g}\left(c_{1}^{b}\right)\right) .
$$


Optimality requires

$$
u^{\prime}\left(\hat{c}_{1}^{g}\left(c_{1}^{b}\right)\right)=\alpha u^{\prime}\left(\hat{c}_{2}^{g}\left(c_{1}^{b}\right)\right)
$$

which implies $\hat{c}_{2}^{g}\left(c_{1}^{b}\right)>\hat{c}_{1}^{g}\left(c_{1}^{b}\right)$. Again, we can determine a critical value $\tilde{\alpha}_{\text {ctd }}$ up to which the first best can be implemented. Under the assumption that $g$-types can buy further annuities, their budget constraint with the first-best lump-sum payment is

$$
c_{1}^{g}+\rho c_{2}^{g}=c_{1}^{b *} .
$$

This compares to a present value of consumption $c_{1}^{g *}+\rho c_{2}^{g *}$ if the annuity is chosen. Thus, the lump-sum option is inferior if $c_{1}^{b *}<c_{1}^{g *}+\rho c_{2}^{g *}$. Using $c_{1}^{b *}=c_{2}^{g *}$ yields the equivalent condition

$$
c_{1}^{b *}<\frac{c_{1}^{g *}}{1-\rho}
$$

which will be met as long as $\alpha$ is sufficiently small. For example, if the utility function is $u\left(c_{t}\right)=\ln \left(c_{t}\right)$, then $c_{2}^{g *}=\alpha c_{1}^{g *}$. In this case, the condition is

$$
\alpha<\frac{1}{1-\rho} \equiv \tilde{\alpha}_{c t d}
$$

In the basic model, $\tilde{\alpha}=1+\rho$. Since $\frac{1}{1-\rho}>1+\rho$, the critical value of $\alpha$ is therefore larger with identical close-to-death utility. The intuition for this result is that $g$ types have less incentives to pretend to be $b$-types if their annuity is higher when old.

As long as $1 \leq \alpha \leq \tilde{\alpha}_{c t d}$, the first best can be implemented by giving individual a choice between the lump-sum payment $c_{1}^{b *}$ and the increasing annuity $c_{1}^{g *}, c_{2}^{g *}$. If $\alpha>\tilde{\alpha}_{c t d}$, the incentive constraint (28) needs to be considered. The Lagrangian is

$$
\begin{aligned}
\mathcal{L}= & \delta\left(\pi\left(u\left(c_{1}^{g}\right)+\rho \alpha u\left(c_{2}^{g}\right)\right)+(1-\pi) \alpha u\left(c_{1}^{b}\right)\right) \\
& +\lambda\left\{\Omega-\delta\left(\pi c_{1}^{g}+\pi \rho c_{2}^{g}+(1-\pi) c_{1}^{b}\right)\right\} \\
& +\mu\left\{u\left(c_{1}^{g}\right)+\rho \alpha u\left(c_{2}^{g}\right)-u\left(\hat{c}_{1}^{g}\left(c_{1}^{b}\right)\right)-\rho \alpha u\left(\hat{c}_{2}^{g}\left(c_{1}^{b}\right)\right)\right\}
\end{aligned}
$$


with the first-order conditions

$$
\begin{aligned}
\frac{\partial \mathcal{L}}{\partial c_{1}^{g}}= & \delta \pi u^{\prime}\left(c_{1}^{g}\right)-\lambda \delta \pi+\mu u^{\prime}\left(c_{1}^{g}\right)=0 \\
\frac{\partial \mathcal{L}}{\partial c_{2}^{g}}= & \delta \pi \rho \alpha u^{\prime}\left(c_{2}^{g}\right)-\lambda \delta \pi \rho+\mu \rho \alpha u^{\prime}\left(c_{2}^{g}\right)=0 \\
\frac{\partial \mathcal{L}}{\partial c_{1}^{b}}= & \delta(1-\pi) \alpha u^{\prime}\left(c_{1}^{b}\right)-\lambda \delta(1-\pi) \\
& -\mu u^{\prime}\left(\hat{c}_{1}^{g}\left(c_{1}^{b}\right)\right) \frac{\mathrm{d} \hat{c}_{1}^{g}}{\mathrm{~d} c_{1}^{b}}-\mu \rho \alpha u^{\prime}\left(\hat{c}_{2}^{g}\left(c_{1}^{b}\right)\right) \frac{\mathrm{d} \hat{c}_{2}^{g}}{\mathrm{~d} c_{1}^{b}}=0 \\
\frac{\partial \mathcal{L}}{\partial \lambda}= & \Omega-\delta\left(\pi c_{1}^{g}+\pi \rho c_{2}^{g}+(1-\pi) c_{1}^{b}\right)=0 \\
\frac{\partial \mathcal{L}}{\partial \mu}= & u\left(c_{1}^{g}\right)+\rho \alpha u\left(c_{2}^{g}\right)-u\left(\hat{c}_{1}^{g}\left(c_{1}^{b}\right)\right)-\rho \alpha u\left(\hat{c}_{2}^{g}\left(c_{1}^{b}\right)\right)=0 .
\end{aligned}
$$

From (30) und (31) we obtain

$$
u^{\prime}\left(c_{1}^{g}\right)=\alpha u^{\prime}\left(c_{2}^{g}\right) \quad \Rightarrow \quad c_{1}^{g}<c_{2}^{g}
$$

and an increasing annuity is optimal for $g$-types. Since $u^{\prime}\left(\hat{c}_{1}^{g}\left(c_{1}^{b}\right)\right)=\alpha u^{\prime}\left(\hat{c}_{2}^{g}\left(c_{1}^{b}\right)\right)$ by (29), the binding incentive constraint (28) implies

$$
c_{1}^{b}=c_{1}^{g}+\rho c_{2}^{g},
$$

i.e. the lump-sum payment for $b$-types and the present value of the annuity for $g$-types are the same. In the first best, we also have an increasing annuity annuity of $g$-types. However, the first-best lump-sum payment is larger than the present value of the annuity if $\alpha>\tilde{\alpha}_{\text {ctd }}$. Thus, the lump-sum payment must be smaller in the second best. The same result holds in the basic model. Again, the optimal solution can be implemented by giving individuals a choice between a lump-sum payment and an annuity.

Proposition 3.3. When the utility function is the same for both types in the period prior to death and marginal utility is larger in this period, choice between a lump-sum payment and an annuity is optimal if the health status is unobservable. The only difference to the basic model is that the annuity must be increasing rather than constant. 


\subsection{Minimum income and moral hazard}

If society grants a minimum income to its citizens, an important concern with respect to lump-sum withdrawals is moral hazard. Individuals may then have the incentive to take the lump sum, spend it regardless of their life expectancy on immediate consumption and rely on public transfers if they live longer. To rule this out, the government may therefore require that individuals only buy pension plans which guarantee a payment that is at least as high as the guaranteed minimum income in each period.

In the following, we examine the consequences of this policy for the second-best pension plan. We denote minimum income by $m$ and assume that in the first best, individuals do not qualify for public assistance, i.e. $c^{g *}, c_{1}^{b *}>m$. If the health status is not observable, the incentive constraint (ICB) for $b$-types and therefore the results for $\alpha<1$ remain unchanged. However, the incentive constraint for $g$-types needs to modified. Since the contract for $b$-types cannot be lump sum, it consists of a payment $c_{1}^{b}$ in period 1 and $m$ in period 2 (which is never paid in the first best). If $g$-types pretend to be $b$-types, they therefore can also claim a payment $m$ in period 2. The present value of the payment for $b$-types is therefore $\left(c_{1}^{b}+\rho m\right) /(1+\rho)$ and the incentive constraint is

$$
u\left(c_{1}^{g}\right)+\rho u\left(c_{2}^{g}\right) \geq(1+\rho) u\left(\left(c_{1}^{b}+\rho m\right) /(1+\rho)\right) .
$$

For a given value of $c_{1}^{b}$, it is therefore more attractive for $g$-types to claim to be $b$-types. This lowers the critical value $\tilde{\alpha}$. For logarithmic utility, we obtain

$$
\tilde{\alpha}_{m}=1+\rho-\frac{\rho m}{c^{g *}}<1+\rho=\tilde{\alpha} \cdot{ }^{15}
$$

As above, the first best is incentive-compatible if $1 \leq \alpha \leq \tilde{\alpha}_{m}$. In this case, individuals can be given a choice between the payment stream $c_{1}^{b *}, m$ and a constant annuity $c^{g *}$. Since $\alpha>1$ implies $c_{1}^{b *}>c^{g *}$, we can interpret $c_{1}^{b *}-c^{g *}$ as a partial lump-sum withdrawal which results in a reduction $c^{g *}-m$ in the second-period payment.

To determine the optimal pension plan for $\alpha>\tilde{\alpha}_{m}$, we solve the problem

$$
\max E U=\delta\left(\pi\left(u\left(c_{1}^{g}\right)+\rho u\left(c_{2}^{g}\right)\right)+(1-\pi) \alpha u\left(c_{1}^{b}\right)\right)
$$

\footnotetext{
${ }^{15}$ Note that $\tilde{\alpha}_{m}>1$ since we assumed $c^{g *}>m$.
} 
s.t.

$$
\begin{gathered}
\Omega=\delta\left(\pi c_{1}^{g}+\pi \rho c_{2}^{g}+(1-\pi) c_{1}^{b}\right) \\
u\left(c_{1}^{g}\right)+\rho u\left(c_{2}^{g}\right)=(1+\rho) u\left(\left(c_{1}^{b}+\rho m\right) /(1+\rho)\right) .
\end{gathered}
$$

Setting up the Lagrangian

$$
\begin{aligned}
\mathcal{L}= & \delta\left(\pi\left(u\left(c_{1}^{g}\right)+\rho u\left(c_{2}^{g}\right)\right)+(1-\pi) \alpha u\left(c_{1}^{b}\right)\right) \\
& +\lambda\left\{\Omega-\delta\left(\pi c_{1}^{g}+\pi \rho c_{2}^{g}+(1-\pi) c_{1}^{b}\right)\right\} \\
& +\mu\left\{u\left(c_{1}^{g}\right)+\rho u\left(c_{2}^{g}\right)-(1+\rho) u\left(\left(c_{1}^{b}+\rho m\right) /(1+\rho)\right)\right\}
\end{aligned}
$$

yields the first-order conditions

$$
\begin{aligned}
& \frac{\partial \mathcal{L}}{\partial c_{1}^{g}}=\delta \pi u^{\prime}\left(c_{1}^{g}\right)-\lambda \delta \pi+\mu u^{\prime}\left(c_{1}^{g}\right)=0 \\
& \frac{\partial \mathcal{L}}{\partial c_{2}^{g}}=\delta \pi \rho u^{\prime}\left(c_{2}^{g}\right)-\lambda \delta \pi \rho+\mu \rho u^{\prime}\left(c_{2}^{g}\right)=0 \\
& \frac{\partial \mathcal{L}}{\partial c_{1}^{b}}=\delta(1-\pi) \alpha u^{\prime}\left(c_{1}^{b}\right)-\lambda \delta(1-\pi)-\mu u^{\prime}\left(\left(c_{1}^{b}+\rho m\right) /(1+\rho)\right)=0 \\
& \frac{\partial \mathcal{L}}{\partial \lambda}=\Omega-\delta\left(\pi c_{1}^{g}+\pi \rho c_{2}^{g}+(1-\pi) c_{1}^{b}\right)=0 \\
& \frac{\partial \mathcal{L}}{\partial \mu}=u\left(c_{1}^{g}\right)+\rho u\left(c_{2}^{g}\right)-(1+\rho) u\left(c_{1}^{b} /(1+\rho)\right)=0 .
\end{aligned}
$$

From (39) und (40) we obtain as in the basic model

$$
u^{\prime}\left(c_{1}^{g}\right)=u^{\prime}\left(c_{2}^{g}\right) \quad \Rightarrow \quad c_{1}^{g}=c_{2}^{g}=c^{g}
$$

Inserting into condition (38) yields

$$
(1+\rho) u\left(c^{g}\right)=(1+\rho) u\left(\left(c_{1}^{b}+\rho m\right) /(1+\rho)\right) \Rightarrow c_{1}^{b}=(1+\rho) c^{g}-\rho m .
$$

Thus, the present value of the payment for $b$-types is smaller than the annuity for g-types. Furthermore, we must have $c_{1}^{b}>c^{g}>m .{ }^{16}$ Therefore, it is optimal to give individuals a choice between a partial lump-sum withdrawal $c_{1}^{b}-c^{g}$ with a reduction $c^{g}-m$ in the second-period payment and a constant annuity paying $c^{g}$.

\footnotetext{
${ }^{16} \mathrm{By}(44), c_{1}^{b} \leq c^{g}$ implies $m \geq c^{g}$. Since we assumed for the first best $c^{g *}>m$, this implies $c^{g}<c^{g *}$ and, by the budget constraint, $c_{1}^{b}>c_{1}^{b *}>m$. Thus, $c_{1}^{b} \leq c^{g}$ is only possible if $c^{g}>m$ which is incompatible with (44). Therefore, we must have $c_{1}^{b}>c^{g}$ and, by (44), $c^{g}>m$.
} 
Proposition 3.4. If the government requires that individuals only buy pensions plans which guarantee a payment that is at least as high as minimum income in each period and the health status is not observable, then the first best can be implemented for a smaller range of $\alpha$. If marginal utility of consumption is higher in the bad health state, it is optimal to give individuals a choice between a partial lump-sum withdrawal and a constant annuity.

\subsection{Positive survival probability for individuals in bad health}

So far, we maintained the assumption that individuals in state $b$ will not live more than one period. Now we allow both types to survive to the second period. The respective survival probabilities are $\rho^{b}$ and $\rho^{g}$ with $0<\rho^{b}<\rho^{g}<1$, i.e. $b$-types have a lower life expectancy. Expected utility is

$$
E U=\delta\left(\pi\left(u\left(c_{1}^{g}\right)+\rho^{g} u\left(c_{2}^{g}\right)\right)+(1-\pi)\left(\alpha u\left(c_{1}^{b}\right)+\rho^{b} \alpha u\left(c_{2}^{b}\right)\right)\right) .
$$

It is straightforward to show that the first-best solution requires annuities $c^{g}$ and $c^{b}$ with

$$
c^{b} \gtrless c^{g} \quad \Leftrightarrow \quad \alpha \gtrless 1 .
$$

If the health status is not observable, then it is impossible to implement the first best unless $\alpha=1$. If $\alpha<1$, then $b$-types pretend to be $g$-types and vice versa. Consequently, one incentive constraint will be binding for $\alpha<1$, the other for $\alpha>1$.

In the following, we assume that pension plans can monitor and thus prohibit further annuity purchases. For simplicity, we also allow pension plans to monitor and rule out savings (see footnote 19).

Second-best solution for $\alpha<1$

In this case, the incentive-constraint for $b$-types

$$
u\left(c_{1}^{b}\right)+\rho^{b} u\left(c_{2}^{b}\right) \geq u\left(c_{1}^{g}\right)+\rho^{b} u\left(c_{2}^{g}\right)
$$


will be binding. Setting up the Lagrangian

$$
\begin{aligned}
\mathcal{L}= & \delta\left(\pi\left(u\left(c_{1}^{g}\right)+\rho^{g} u\left(c_{2}^{g}\right)\right)+(1-\pi)\left(\alpha u\left(c_{1}^{b}\right)+\rho^{b} \alpha u\left(c_{2}^{b}\right)\right)\right) \\
& +\lambda\left\{\Omega-\delta\left(\pi c_{1}^{g}+\pi \rho^{g} c_{2}^{g}+(1-\pi) c_{1}^{b}+(1-\pi) \rho^{b} c_{2}^{b}\right)\right\} \\
& +\mu\left\{u\left(c_{1}^{b}\right)+\rho^{b} u\left(c_{2}^{b}\right)-u\left(c_{1}^{g}\right)-\rho^{b} u\left(c_{2}^{g}\right)\right\}
\end{aligned}
$$

yields the first-order conditions

$$
\begin{aligned}
& \frac{\partial \mathcal{L}}{\partial c_{1}^{g}}=\delta \pi u^{\prime}\left(c_{1}^{g}\right)-\lambda \delta \pi-\mu u^{\prime}\left(c_{1}^{g}\right)=0 \\
& \frac{\partial \mathcal{L}}{\partial c_{2}^{g}}=\delta \pi \rho^{g} u^{\prime}\left(c_{2}^{g}\right)-\lambda \delta \pi \rho^{g}-\mu \rho^{b} u^{\prime}\left(c_{2}^{g}\right)=0 \\
& \frac{\partial \mathcal{L}}{\partial c_{1}^{b}}=\delta(1-\pi) \alpha u^{\prime}\left(c_{1}^{b}\right)-\lambda \delta(1-\pi)+\mu u^{\prime}\left(c_{1}^{b}\right)=0 \\
& \frac{\partial \mathcal{L}}{\partial c_{2}^{b}}=\delta(1-\pi) \rho^{b} \alpha u^{\prime}\left(c_{2}^{b}\right)-\lambda \delta(1-\pi) \rho^{b}+\mu \rho^{b} u^{\prime}\left(c_{2}^{b}\right)=0 \\
& \frac{\partial \mathcal{L}}{\partial \lambda}=\Omega-\delta\left(\pi c_{1}^{g}+\pi \rho^{g} c_{2}^{g}+(1-\pi) c_{1}^{b}+(1-\pi) \rho^{b} c_{2}^{b}\right)=0 \\
& \frac{\partial \mathcal{L}}{\partial \mu}=u\left(c_{1}^{b}\right)+\rho^{b} u\left(c_{2}^{b}\right)-u\left(c_{1}^{g}\right)-\rho^{b} u\left(c_{2}^{g}\right)=0 .
\end{aligned}
$$

We obtain $c_{1}^{b}=c_{2}^{b}$ from (49) and (50). Conditions (47) and (48) yield

$$
u^{\prime}\left(c_{1}^{g}\right)=\frac{\lambda \pi}{\delta \pi-\mu} \quad \text { and } \quad u^{\prime}\left(c_{2}^{g}\right)=\frac{\lambda \pi}{\delta \pi-\mu \frac{\rho^{b}}{\rho^{g}}} \cdot{ }^{17}
$$

Since $\rho^{g}>\rho^{b}$, this implies

$$
u^{\prime}\left(c_{2}^{g}\right)<u^{\prime}\left(c_{1}^{g}\right) \quad \Rightarrow \quad c_{2}^{g}>c_{1}^{g} .
$$

Thus, the incentive for $b$-types to pretend to be $g$-types is countered by an increasing annuity which is less attractive for $b$-types. From the binding incentive constraint (46), we obtain the solution

$$
c_{2}^{g}>c_{1}^{b}=c_{2}^{b}>c_{1}^{g} .
$$

Thus, it is optimal to give individuals a choice between a constant and an increasing annuity in period 1 .

\footnotetext{
${ }^{17}$ The assumption $\lim _{c_{t} \rightarrow 0} u^{\prime}\left(c_{t}\right)=\infty$ ensures positive marginal utilities.
} 
Second-best solution for $\alpha>1$

In this case, the incentive-constraint for $g$-types

$$
u\left(c_{1}^{g}\right)+\rho^{g} u\left(c_{2}^{g}\right) \geq u\left(c_{1}^{b}\right)+\rho^{g} u\left(c_{2}^{b}\right)
$$

will be binding. The Lagrange function is

$$
\begin{aligned}
\mathcal{L}= & \delta\left(\pi\left(u\left(c_{1}^{g}\right)+\rho^{g} u\left(c_{2}^{g}\right)\right)+(1-\pi)\left(\alpha u\left(c_{1}^{b}\right)+\rho^{b} \alpha u\left(c_{2}^{b}\right)\right)\right) \\
& +\lambda\left\{\Omega-\delta\left(\pi c_{1}^{g}+\pi \rho^{g} c_{2}^{g}+(1-\pi) c_{1}^{b}+(1-\pi) \rho^{b} c_{2}^{b}\right)\right\} \\
& +\mu\left\{u\left(c_{1}^{g}\right)+\rho^{g} u\left(c_{2}^{g}\right)-u\left(c_{1}^{b}\right)-\rho^{g} u\left(c_{2}^{b}\right)\right\} .
\end{aligned}
$$

The first-order conditions are

$$
\begin{aligned}
& \frac{\partial \mathcal{L}}{\partial c_{1}^{g}}=\delta \pi u^{\prime}\left(c_{1}^{g}\right)-\lambda \delta \pi+\mu u^{\prime}\left(c_{1}^{g}\right)=0 \\
& \frac{\partial \mathcal{L}}{\partial c_{2}^{g}}=\delta \pi \rho^{g} u^{\prime}\left(c_{2}^{g}\right)-\lambda \delta \pi \rho^{g}+\mu \rho^{g} u^{\prime}\left(c_{2}^{g}\right)=0 \\
& \frac{\partial \mathcal{L}}{\partial c_{1}^{b}}=\delta(1-\pi) \alpha u^{\prime}\left(c_{1}^{b}\right)-\lambda \delta(1-\pi)-\mu u^{\prime}\left(c_{1}^{b}\right)=0 \\
& \frac{\partial \mathcal{L}}{\partial c_{2}^{b}}=\delta(1-\pi) \rho^{b} \alpha u^{\prime}\left(c_{2}^{b}\right)-\lambda \delta(1-\pi) \rho^{b}-\mu \rho^{g} u^{\prime}\left(c_{2}^{b}\right)=0 \\
& \frac{\partial \mathcal{L}}{\partial \lambda}=\Omega-\delta\left(\pi c_{1}^{g}+\pi \rho^{g} c_{2}^{g}+(1-\pi) c_{1}^{b}+(1-\pi) \rho^{b} c_{2}^{b}\right)=0 \\
& \frac{\partial \mathcal{L}}{\partial \mu}=u\left(c_{1}^{g}\right)+\rho^{g} u\left(c_{2}^{g}\right)-u\left(c_{1}^{b}\right)-\rho^{g} u\left(c_{2}^{b}\right)=0 .
\end{aligned}
$$

We obtain $c_{1}^{g}=c_{2}^{g}$ from (54) and (55). Conditions (56) and (57) lead to

$$
u^{\prime}\left(c_{1}^{b}\right)=\frac{\lambda(1-\pi)}{\delta(1-\pi) \alpha-\mu} \quad \text { and } \quad u^{\prime}\left(c_{2}^{b}\right)=\frac{\lambda(1-\pi)}{\delta(1-\pi) \alpha-\mu \frac{\rho^{g}}{\rho^{b}}}{ }^{18}
$$

Since $\rho^{g}>\rho^{b}$, we obtain

$$
u^{\prime}\left(c_{1}^{b}\right)<u^{\prime}\left(c_{2}^{b}\right) \quad \Leftrightarrow \quad c_{1}^{b}>c_{2}^{b} \cdot 19
$$

\footnotetext{
${ }^{18}$ The assumption $\lim _{c_{t} \rightarrow 0} u^{\prime}\left(c_{t}\right)=\infty$ ensures positive marginal utilities.

${ }^{19} \mathrm{We}$ assumed that pension plans can prohibit savings. This is necessary if the optimal solution implies $u^{\prime}\left(c_{1}^{b}\right)<\rho^{h} u^{\prime}\left(c_{2}^{b}\right), h=g, b$. If savings cannot be monitored then the additional constraint $u^{\prime}\left(c_{1}^{b}\right) \geq \rho^{g} u^{\prime}\left(c_{2}^{b}\right)$ needs to be imposed which implies $u^{\prime}\left(c_{1}^{b}\right) \geq \rho^{b} u^{\prime}\left(c_{2}^{b}\right)$.
} 
Finally, using the binding incentive constraint (53) yields

$$
c_{1}^{b}>c_{1}^{g}=c_{2}^{g}>c_{2}^{b}
$$

This solution can be implemented by allowing individuals a choice between a partial lump-sum withdrawal $c_{1}^{b}-c^{g}$ with a reduction $c^{g}-c_{2}^{b}$ in the second-period payment and a constant annuity $c^{g}$.

Proposition 3.5. If individuals in bad health have a positive probability to survive to period 2 and a lower life expectancy, the first best cannot be implemented if the health status is not observable. Assuming that pension plans can rule out further annuity purchases and savings, it is optimal to give individuals a choice between a partial lump-sum withdrawal and a constant annuity if life expectancy and marginal utility are negatively correlated. Otherwise, choice between a constant and an increasing annuity is preferable.

\section{Implications for public pensions}

So far, we have left open whether the pension plan is private or public. Since we assumed that individuals are ex ante identical, however, there seems to be little justification for public intervention. This changes if we consider that individuals differ already ex ante in their type. ${ }^{20}$ Assume that a share $\pi$ lives for certain for one period and with probability $\rho$ for two periods, and a share $1-\pi$ lives only for one period. The types are unobservable and the utility of consumption differs as in the analysis above. For an utilitarian social planner the social welfare function is then equivalent to the expected utility function (1). Thus, it is optimal for the social planner to use a lump-sum option if marginal utility of consumption and life expectancy are negatively correlated.

Furthermore, one can make an argument in favor of a lump-sum option even if the utility function in each period is not state-dependent, i.e. the per period utility

\footnotetext{
${ }^{20}$ In Diamond (2003, Chapter 7) individuals differ ex ante in productivity which is positively correlated with life expectancy. In an optimal income tax framework, he shows that a lumpsum option can increase social welfare since it will be chosen by the individuals with low life expectancy. As an additional screening device, it benefits individuals with low productivity.
} 


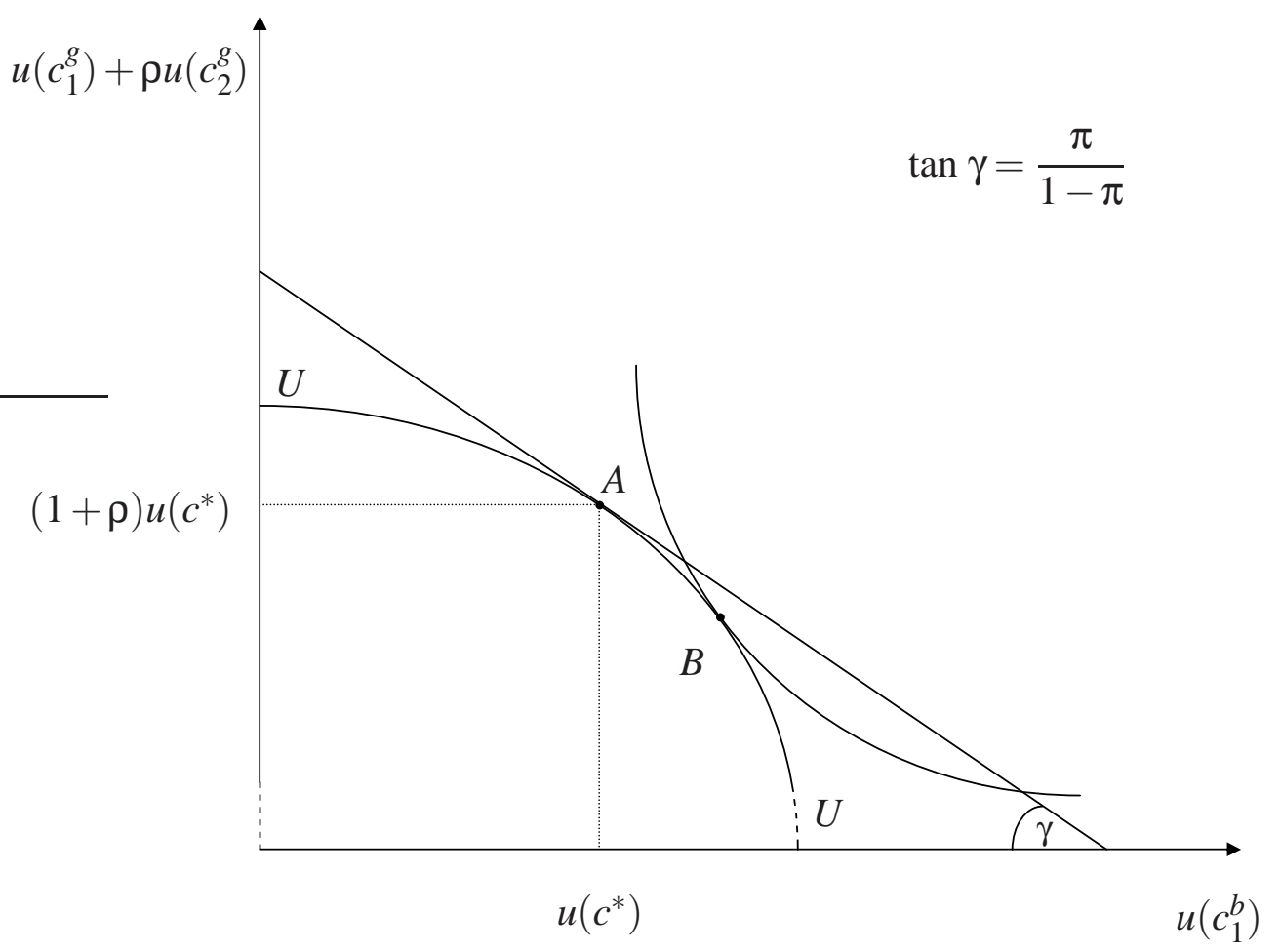

Figure 4: Optimal pension plans and social welfare

function is always $u\left(c_{t}\right) \cdot{ }^{21}$ Consider the social welfare function

$$
\begin{aligned}
\mathcal{W} & =(1-\pi) W\left(E U^{g}\right)+\pi W\left(E U^{b}\right) \\
& =(1-\pi) W\left(u\left(c_{1}^{g}\right)+\rho u\left(c_{2}^{g}\right)\right)+\pi W\left(u\left(c_{1}^{b}\right)\right)
\end{aligned}
$$

with $W^{\prime}>0, W^{\prime \prime} \leq 0$. In the utilitarian case $W^{\prime \prime}=0$, the objective function is equivalent to the expected utility function (1) for $\alpha=1$. A constant annuity annuity $c^{*}$ is therefore optimal. This situation is illustrated by allocation $A$ in Figure 4. $U U$ is the utility possibility frontier which must be strictly concave due to $u^{\prime \prime}<0$. At point $A$, the marginal rate of substitution between the expected utility of both types is

$$
-\left.\frac{\mathrm{d} E U^{g}}{\mathrm{~d} E U^{b}}\right|_{\mathrm{d} w=0}=\frac{\pi}{1-\pi} .
$$

In $A$, we have $E U^{g}=(1+\rho) u\left(c^{*}\right)>u\left(c^{*}\right)=E U^{b}$. If the social welfare function is

\footnotetext{
${ }^{21}$ I thank Jean-Marie Lozachmeur for making me aware of this interpretation.
} 
strictly concave, i.e. $W^{\prime \prime}<0$, the social planner will therefore want to redistribute to individuals with lower total expected utility, i.e. those with low life expectancy. The optimal point will be to the right of point $A$, for instance in point $B$. Here the marginal rate of substitution is given by

$$
-\left.\frac{\mathrm{d} E U^{g}}{\mathrm{~d} E U^{b}}\right|_{\mathrm{d} w=0}=\frac{\pi}{1-\pi} \frac{W^{\prime}\left(E U^{b}\right)}{W^{\prime}\left(E U^{g}\right)}>\frac{\pi}{1-\pi} .
$$

Now define $\alpha \equiv W^{\prime}\left(E U^{b}\right) / W^{\prime}\left(E U^{g}\right)>1$. Then the maximization of the social welfare function (60) is equivalent to maximization of expected utility (1) with $\alpha>1$. Thus, we can reinterpret $\alpha>1$ as the relative welfare weight given to individuals with low life expectancy at the optimum. This shows that a lumpsum withdrawal option can also be justified on pure equity grounds without the assumption of a state-dependent utility function. If $\alpha$ is smaller than the critical value $\tilde{\alpha}$, the first-best can be implemented; otherwise the incentive constraint for individuals with high life expectancy will be binding and only a second-best solution is possible.

Proposition 4.1. If types differ ex ante in life expectancy and the social planner maximizes a utilitarian social welfare function, it is optimal to give individuals a choice between a lump-sum payment and an annuity if life expectancy and marginal utility of consumption are negatively correlated. If social welfare is strictly concave in the types' total expected utility, this choice is optimal even if the marginal utility of consumption is independent of life expectancy. 


\section{Conclusion}

This paper examined the optimal design of pension plans when the health status during retirement is uncertain. In contrast to standard models, we assumed that the health status affects both life expectancy and the marginal utility of consumption. A simple model demonstrated that choice between a lump-sum payment and an annuity can be welfare-enhancing if the health status is not observable. This result holds if the marginal utility of consumption and life expectancy are negatively correlated. This result proved robust in several extensions. For example, we allowed marginal utility of consumption to be imperfectly correlated with the health status and considered that the maximum life-span does not depend on the health status. In the latter case, the possibility of a partial lump-sum withdrawal proved to be optimal if marginal utility of consumption and life expectancy are negatively correlated. Furthermore, we showed that a lump-sum option can be justified on equity grounds. When the social welfare function is strictly concave, this result holds even if the marginal utility of consumption is independent of life expectancy.

A limitation of the analysis is that we assumed a uniform retirement age. However, health and life expectancy can be expected to have an impact on the retirement age as well. For example, McGarry (2004) finds that the less healthy are likely to retire earlier. Similarly, Hurd, Smith, and Zissimopoulos (2004) observe that those with very low subjective probabilities of survival choose a lower retirement age. An interesting question for future research is whether early retirement and lump-sum payments are substitutes if individuals value consumption higher when their health state is bad.

Finally, the paper raises the empirical question on how health affects utility and life expectancy of the elderly. In particular, it would be interesting to investigate the correlation of marginal utility of consumption and life expectancy in old age. As this paper shows this correlation is crucial for the optimal design of pension plans. 


\section{References}

Bernheim, B. (1991). "How Strong Are Bequest Motives? Evidence Based on Estimates of the Demand for Life Insurance and Annuities," Journal of Political Economy 99, 899-927.

Brown, J., and J. Poterba (2000). "Joint Life Annuities and Annuity Demand by Married Couples," Journal of Risk and Insurance 67, 527-553.

Brugiavini, A. (1993). "Uncertain Resolution and the Timing of Annuity Purchases," Journal of Public Economics 50, 31-62.

Davidoff, T., J. Brown, and P. Diamond (2005). "Annuities and Individual Welfare," American Economic Review 95, 1573-1590.

Diamond, P. (2003). Taxation, Incomplete Markets, and Social Security. Munich Lectures in Economics MIT Press: Cambridge, Massachusetts.

Direr, A. (2007). "Flexible Life Annuities," Discussion paper, University of Grenoble.

Evans, W., and W. Viscusi (1991). "Estimation of State-Dependent Utility Functions Using Survey Data," Review of Economics and Statistics 73, 94-104.

Friedman, B., and M. Warshawsky (1988). "Annuity Prices and Saving Behavior in the United States," in Z. Bodie, J. Shoven, and D. Wise (ed.), Pensions in the U.S. Economy pp. 53-77 University of Chicago Press: Chicago.

Friedman, B., and M. Warshawsky (1990). "The Cost of Annuities: Implication for Saving Behavior and Bequests," Quarterly Journal of Economics 105, 135154.

Hurd, M. (1989). “Mortality Risk and Bequest,” Econometrica 57, 779-813.

Hurd, M., and K. McGarry (1995). "Evaluation of the Subjective Probabilities of Survival in the Health and Retirement Study," Journal of Human Resources 30, S268-S292. 
Hurd, M., J. Smith, and J. Zissimopoulos (2004). “The Effects of Subjective Survival on Retirement and Social Security Claiming," Journal of Applied Econometrics 19, 761-775.

Kotlikoff, L., and A. Spivak (1981). "The Family as an Incomplete Annuities Market," Journal of Political Economy 89, 372-391.

Kotlikoff, L., and L. Summers (1981). "The Role of Intergenerational Transfers in Aggregate Capital Accumulation,” Journal of Political Economy 89, 706-732.

McGarry, K. (2004). "Health and Retirement: Do Changes in Health Affect Retirement Expectations?," Journal of Human Resources 39, 624-648.

Mitchell, O., J. Poterba, M. Warshawsky, and J. Brown (1999). "New Evidence on the Money's Worth of Individual Annuities," American Economic Review 89, 1299-1318.

Sheshinski, E. (2004). “Annuities and Retirement,” in C.D. Aliprantis, K.J. Arrow, P. Hammond, F. Kubler, H-M. Wu, and N.C. Yannelis (ed.), Assets, Beliefs, and Equilibria in Economic Dynamics: Essays in Honor of Mordecai Kurz pp. 2754 Springer: Berlin.

Viscusi, W., and W. Evans (1990). "Utility Functions that Depend on Health Status: Estimates and Economic Implications," American Economic Review 80, 353-374.

Yaari, M. (1965). "Uncertain Lifetime, Life Insurance, and the Theory of the Consumer," Review of Economic Studies 32, 137-150.

Yagi, T., and Y. Nishigaki (1993). "The Inefficiency of Private Constant Annuities," Journal of Risk and Insurance 60, 385-412.

Zhang, J., and K. Tang (2007). "Morbidity, Mortality, Health Expenditure and Annuitization,' Discussion paper, School of Economics, University of Queensland. 


\section{CESifo Working Paper Series}

for full list see www.cesifo-group.org/wp

(address: Poschingerstr. 5, 81679 Munich, Germany, office@cesifo.de)

2148 Andreas Irmen and Rainer Klump, Factor Substitution, Income Distribution, and Growth in a Generalized Neoclassical Model, November 2007

2149 Lorenz Blume, Jens Müller and Stefan Voigt, The Economic Effects of Direct Democracy - A First Global Assessment, November 2007

2150 Axel Dreher, Pierre-Guillaume Méon and Friedrich Schneider, The Devil is in the Shadow - Do Institutions Affect Income and Productivity or only Official Income and Official Productivity?, November 2007

2151 Valentina Bosetti, Carlo Carraro, Emanuele Massetti and Massimo Tavoni, International Energy R\&D Spillovers and the Economics of Greenhouse Gas Atmospheric Stabilization, November 2007

2152 Balázs Égert and Dubravko Mihaljek, Determinants of House Prices in Central and Eastern Europe, November 2007

2153 Christa Hainz and Hendrik Hakenes, The Politician and his Banker, November 2007

2154 Josef Falkinger, Distribution and Use of Knowledge under the "Laws of the Web", December 2007

2155 Thorvaldur Gylfason and Eduard Hochreiter, Growing Apart? A Tale of Two Republics: Estonia and Georgia, December 2007

2156 Morris A. Davis and François Ortalo-Magné, Household Expenditures, Wages, Rents, December 2007

2157 Andreas Haufler and Christian Schulte, Merger Policy and Tax Competition, December 2007

2158 Marko Köthenbürger and Panu Poutvaara, Rent Taxation and its Intertemporal Welfare Effects in a Small Open Economy, December 2007

2159 Betsey Stevenson, Title IX and the Evolution of High School Sports, December 2007

2160 Stergios Skaperdas and Samarth Vaidya, Persuasion as a Contest, December 2007

2161 Morten Bennedsen and Christian Schultz, Arm's Length Provision of Public Services, December 2007

2162 Bas Jacobs, Optimal Redistributive Tax and Education Policies in General Equilibrium, December 2007 
2163 Christian Jaag, Christian Keuschnigg and Mirela Keuschnigg, Pension Reform, Retirement and Life-Cycle Unemployment, December 2007

2164 Dieter M. Urban, Terms of Trade, Catch-up, and Home Market Effect: The Example of Japan, December 2007

2165 Marcelo Resende and Rodrigo M. Zeidan, Lionel Robbins: A Methodological Reappraisal, December 2007

2166 Samuel Bentolila, Juan J. Dolado and Juan F. Jimeno, Does Immigration Affect the Phillips Curve? Some Evidence for Spain, December 2007

2167 Rainald Borck, Federalism, Fertility and Growth, December 2007

2168 Erkki Koskela and Jan König, Strategic Outsourcing, Profit Sharing and Equilibrium Unemployment, December 2007

2169 Egil Matsen and Øystein Thøgersen, Habit Formation, Strategic Extremism and Debt Policy, December 2007

2170 Torben M. Andersen and Allan Sørensen, Product Market Integration and Income Taxation: Distortions and Gains from Trade, December 2007

2171 J. Atsu Amegashie, American Idol: Should it be a Singing Contest or a Popularity Contest?, December 2007

2172 Patricia Apps and Ray Rees, Household Models: An Historical Perspective, December 2007

2173 Ben Greiner, Axel Ockenfels and Peter Werner, The Dynamic Interplay of Inequality and Trust - An Experimental Study, December 2007

2174 Michael Melvin and Magali Valero, The Dark Side of International Cross-Listing: Effects on Rival Firms at Home, December 2007

2175 Gebhard Flaig and Horst Rottmann, Labour Market Institutions and the Employment Intensity of Output Growth. An International Comparison, December 2007

2176 Alexander Chudik and M. Hashem Pesaran, Infinite Dimensional VARs and Factor Models, December 2007

2177 Christoph Moser and Axel Dreher, Do Markets Care about Central Bank Governor Changes? Evidence from Emerging Markets, December 2007

2178 Alessandra Sgobbi and Carlo Carraro, A Stochastic Multiple Players Multi-Issues Bargaining Model for the Piave River Basin, December 2007

2179 Christa Hainz, Creditor Passivity: The Effects of Bank Competition and Institutions on the Strategic Use of Bankruptcy Filings, December 2007 
2180 Emilia Del Bono, Andrea Weber and Rudolf Winter-Ebmer, Clash of Career and Family: Fertility Decisions after Job Displacement, January 2008

2181 Harald Badinger and Peter Egger, Intra- and Inter-Industry Productivity Spillovers in OECD Manufacturing: A Spatial Econometric Perspective, January 2008

2182 María del Carmen Boado-Penas, Salvador Valdés-Prieto and Carlos Vidal-Meliá, the Actuarial Balance Sheet for Pay-As-You-Go Finance: Solvency Indicators for Spain and Sweden, January 2008

2183 Assar Lindbeck, Economic-Social Interaction in China, January 2008

2184 Pierre Dubois, Bruno Jullien and Thierry Magnac, Formal and Informal Risk Sharing in LDCs: Theory and Empirical Evidence, January 2008

2185 Roel M. W. J. Beetsma, Ward E. Romp and Siert J. Vos, Intergenerational Risk Sharing, Pensions and Endogenous Labor Supply in General Equilibrium, January 2008

2186 Lans Bovenberg and Coen Teulings, Rhineland Exit?, January 2008

2187 Wolfgang Leininger and Axel Ockenfels, The Penalty-Duel and Institutional Design: Is there a Neeskens-Effect?, January 2008

2188 Sándor Csengődi and Dieter M. Urban, Foreign Takeovers and Wage Dispersion in Hungary, January 2008

2189 Joerg Baten and Andreas Böhm, Trends of Children's Height and Parental Unemployment: A Large-Scale Anthropometric Study on Eastern Germany, 1994 2006, January 2008

2190 Chris van Klaveren, Bernard van Praag and Henriette Maassen van den Brink, A Public Good Version of the Collective Household Model: An Empirical Approach with an Application to British Household Data, January 2008

2191 Harry Garretsen and Jolanda Peeters, FDI and the Relevance of Spatial Linkages: Do third Country Effects Matter for Dutch FDI?, January 2008

2192 Jan Bouckaert, Hans Degryse and Theon van Dijk, Price Discrimination Bans on Dominant Firms, January 2008

2193 M. Hashem Pesaran, L. Vanessa Smith and Takashi Yamagata, Panel Unit Root Tests in the Presence of a Multifactor Error Structure, January 2008

2194 Tomer Blumkin, Bradley J. Ruffle and Yosef Ganun, Are Income and Consumption Taxes ever really Equivalent? Evidence from a Real-Effort Experiment with Real Goods, January 2008

2195 Mika Widgrén, The Impact of Council's Internal Decision-Making Rules on the Future EU, January 2008 
2196 Antonis Adam, Margarita Katsimi and Thomas Moutos, Inequality and the Import Demand Function, January 2008

2197 Helmut Seitz, Democratic Participation and the Size of Regions: An Empirical Study Using Data on German Counties, January 2008

2198 Theresa Fahrenberger and Hans Gersbach, Minority Voting and Long-term Decisions, January 2008

2199 Chiara Dalle Nogare and Roberto Ricciuti, Term Limits: Do they really Affect Fiscal Policy Choices?, January 2008

2200 Andreas Bühn and Friedrich Schneider, MIMIC Models, Cointegration and Error Correction: An Application to the French Shadow Economy, January 2008

2201 Seppo Kari, Hanna Karikallio and Jukka Pirttilä, Anticipating Tax Change: Evidence from the Finnish Corporate Income Tax Reform of 2005, January 2008

2202 Walter Krämer and André Güttler, On Comparing the Accuracy of Default Predictions in the Rating Industry, January 2008

2203 Syed M. Ahsan and Panagiotis Tsigaris, The Efficiency Loss of Capital Income Taxation under Imperfect Loss Offset Provisions, January 2008

2204 P. Mohnen, F. C. Palm, S. Schim van der Loeff and A. Tiwari, Financial Constraints and other Obstacles: Are they a Threat to Innovation Activity?, January 2008

2205 Sascha O. Becker and Mathias Hoffmann, Equity Fund Ownership and the CrossRegional Diversification of Household Risk, January 2008

2206 Pedro R. D. Bom and Jenny E. Ligthart, How Productive is Public Capital? A MetaAnalysis, January 2008

2207 Martin Werding, Ageing and Productivity Growth: Are there Macro-level Cohort Effects of Human Capital?, January 2008

2208 Frederick van der Ploeg and Steven Poelhekke, Globalization and the Rise of MegaCities in the Developing World, February 2008

2209 Sara Biancini, Regulating National Firms in a Common Market, February 2008

2210 Jin Cao and Gerhard Illing, Liquidity Shortages and Monetary Policy, February 2008

2211 Mathias Kifmann, The Design of Pension Pay Out Options when the Health Status during Retirement is Uncertain, February 2008 